\title{
Pareceres
}

\section{O papel legal do Prefeito em Minas Geraes, nos Municipios de aguas mineraes (1)}

Ruy Barbosa.

Attendendo ao officio, com que me honrou, em 9 deste mez, o illustre prefeito de Poços de Caldas, e, em satisfação do que elle me requeria, tendo examinado

a consulta que elle me submetteu, na mesma data, em cinco paginas da sua letra, mais os quesitos a ella addicionados em 24 do corrente, tambem do seu punho, papeis esses que voltam por mim rubricados, acerca das objecções oppostas ao acto dessa prefeitura, que solicitou do conselho Deliberativo autorização para um emprestimo destinado ao. pagamento das dividas contrahidas para as obras e melhoramento da cidade;

as mensagens endereçadas pela mesma prefeitura ao. conselho Deliberativo em 18 e 30 do mez passado;

a consulta (por copia, como as mensagens) dirigida pelo conselho Deliberativo a um eminente jurista brasileiro;

a copia, que a acompanha, do parecer com que lhe respondeu o douto profissional;

o juizo a que cheguei sobre o assumpto controverso, é o que vou expor, alterando, para melhor deducção das minhas ideas, a ordem na qual se me propõem os quesitos formulados.

(1) Por nimia gentileza de um antigo alumno da Faculdade de Direito de São Paulo, publica-se este parecer inedito de Ruy Barbosa. 
O elemento decisivo na questão suscitada por este caso, com que se está vendo embaraçada, em relações juridicas tão importantes, a administração de Poços de Caldas, está no conceito com que se haja de qualificar e definir o papel legal do prefeito, em Minas, nos municipios de aguas mineraes, cuja organisação as instituições do Estado singularizam com um regimen especial entre as outras municipalidades.

Esse conceito, no meu humilde sentir, não pode ser 0 que lhe attribue o mestre pelo conselho Deliberativo. E' o que tentarei demonstrar, embora alongando-me, para mostrar como não divirjo de tamanha autoridade senão forçado pela boa razão com argumentos irrecusaveis.

A consideração de ser o governo do Estado quem o nomeia não basta, para dar ao prefeito do municipio o caracter de funccionario puramente estadoal, e muito menos, para o reduzir a "mero intermediario do presidente do Estado".

Em França o prefeito de Paris, com ser nomeado pelo governo central, é ao mesmo tempo, como maire da cidade, o mais elevado orgam da administração municipal.

Assim o ensinam, alli, os mestres: "Le rôle général du préfet de la Seine est, en principe, le même que celui des autres préfets; mais, outre sa double mission de réprésentant de l'Etat et réprésentant du département, il droit être envisagé comme maire de Paris,". (Pandectes Françaises, vol. 59, pag. 646, vol. Ville de Paris, n. $^{\circ} 85$ ).

"Tres sortes de funcções tem o prefeito do Sena", diz DUCROCQ: "é o agente do governo, o administrador do departamento e o maire central da cidade de Paris". (Cours de Droit Administrat, $7^{\circ}$ ed., tom. I, n.w 402, pg. 491).

Dahi resulta que "nem sempre é facil discernir em que qualidade procedeu o prefeito do Sena", tendo-se estabelecido incumbir ao presidente da Republica decidir, em conselho de Estado, nos casos controversos, "quando o prefeito do 
Sena obrou como representante dos interesses particulares da cidade de Paris, quando como representante da administração superior". (Pandectes Franç., ibid, n. ${ }^{\circ} 87$ ).

Com os outros maires acontece o contrario. São, desde a lei de 28 de março de 1882 , arts. $73, \S 10^{\circ}$ e 76 , eleitos, em todas as communas francezas pelo conselho municipal. Mas não obstante a procedencia municipal da sua nomeação, não obstante a sua origem exclusivamente municipal, accumulam, com o posto de primeiros magistrados executivos da municipalidade, o de agente do governo da nação.

São das Pandectas Francezas estas palavras: "O maire, magistrado municipal, é, ao mesmo tempo, na communa, o representante da autoridade superior, e tem, por força deste titulo, o encargo de nella assegurar, assim o conhecimento e respeito do lei, como a execução de todas as providencias de segurança geral". (Pandect. Franç., vol. 19, pg. 14. Vo Commune, . $^{\circ}$ 1412).

$\mathrm{E}$ o que já notavam os tratadistas mais antigos, como DUCROCQ: "O maire é, a um tempo, de uma parte, magistrado municipal e chefe da associação communal, de outra parte, o representante e agente do governo". (Cours de Dr. Adm., tom. I, n. ${ }^{0} 265$, pg. 307 e 309). E' o autor mesmo quem gripha os vocabulos, que acabo de sublinhar, observando que a primeira destas considerações "justifica a eleição do maire" pelo conselho municipal, e a segunda, "autoriza o poder executivo a reivindicar o direito de escolher". (Ibid. pags. 307 e 308 ).

Esta coexistencia da expressão municipal com a expressão geral na mesma individualidade administrativa alli ainda se accentua com a persistencia, no poder executivo, do direito, que a reforma de 1882 lhe manteve, de exonerar por decreto e suspender por decisão do prefeito esses funccionarios, eleitos pelos conselhos municipaes. (Ducrocq Op., pg. 314).

Esses funccionarios, pois, cuja autoridade, na sua collação, emana exclusivamente de uma eleição municipal, são, todavia, alem de suspensiveis mediante resolução das prefei- 
turas, exoneraveis por deliberação presidencial, reunindo em si, nas funcções que the são commettidas, a condição de mandatarios legaes do chefe da nação á de mandatarios electivos das communas, a que se acham prepostos.

E' ao que procura dar o maior relevo Mauricio Haurio$c e$, na ultima edição da sua obra classica de direito administrativo, escrevendo: "O maire" (intendente, alcaide, ou prefeito municipal) "tem attribuições provenientes das suas duas qualidades (de sa double qualité); porquanto é, juntamente, representante do Estado, como autoridade do poder regional e orgam executivo da communa". (Precis de Droit Administratif et de Dr. Publ. 8. ${ }^{\mathrm{a}}$ ed. 1914. pag. 305).

$O$ autor accrescenta que "cumpre distinguir com cuidado essas duas qualidades"; o que faz num longo trabalho discriminativo. (Ibid. pags. 305-311).

A origem, portanto, da investidura não communica necessariamente ao funccionario, que a recebe, o caracter exclusivo do poder, que o nomeia, ou elege. E' o que evidenciam esses dois exemplos convergentes. Num caso (o do prefeito da capital da França) o funccionario, nomeado pelo governo da republica, junta em si, com as funcções de seu agente, as de chefe da administração da municipalidade. No outro (o dos maires), esses funccionarios, designados electivamente pelas municipalidades, associam á missão de cabeças do executivo municipal, a de mandatarios do chefe do Estado.

Não é, logo, a investidura, a proveniencia da sua nomeação o que localiza o funcionario nesta ou naquella esphera, nesta ou naquella região administrativa. E' a natureza das attribuições, que lhe commette a lei. Esta pode vincular um mandato do Estado a um cargo da municipalidade, por ella provido, ou ligar um mandato municipal a um cargo de nomeação do Estado. Em ambas as hypotheses dois são os mandatos, um local, outro geral, duas as cathegorias de funcções, umas geraes outras locaes, coassociadas na mesma entidade, embora esta se constitua sempre unilateralmente, ora 
por actos da administração da localidade, ora por actos da administração central.

O mesmo se vê na Belgica. Alli os intendentes municipais (maires) se chamam burgomestres. Segundo a lei de $1 .^{\circ}$ de março de 1848, que ainda hoje alli rege o assumpto, o rei é quem nomeia os burgomestres. (Pandectes Belges, tom. 14, col. 242V ${ }^{\circ}$ Bourgmestre, $\mathrm{n}^{\circ \mathrm{s}} 4$ e 5). Em consequencia dessa nomeação é elle, "delegado do governo quanto a certos ramos da administração geral do reino". Mas tambem é "o primeiro magistrado, o chefe da communa, pelo art. 108 da Constit." (Ibid, col. 241. n. 1).

E, "se ha quem affecte ver no burgomestre", dizem as Pandectas Belgas, "principalmente o agente do poder central encarregado, neste caracter, da execução assim das leis como dos decretos régios nas suas relações com os interesses geraes", "essa não é senão uma das faces da autoridade do burgomestre, e, seguramente, não a principal. 0 burgomestre é, antes de tudo, o chefe da administração municipal: eis a essencia mesma da sua personalidade administrativa, a sua razão de ser". (Pandect. Belges, loc. cit., col. 242, n. 7).

$\mathrm{E}$, proseguindo neste rumo, discorre o tratadista das Pandectas Belgas, observando que, se forçoso fosse ter a mira "na harmonia entre a maneira da instituição do burgomestre e as suas attribuições, parece que, sendo o caracter municipal o preponderante, (o que ninguem contesta), o accessorio deveria seguir o principal". (Ibidem).

Com este argumento se combate alli a nomeação dos burgomestres pelo rei; e, como se pretenda que, "para collaborar na execução das leis e regulamentos de administração geral, necessariamente convem que o poder central receba o burgomestre a sua investidura", responde o abalizado expositor belga, mostrando quantos exemplos existem "de agentes associados ao poder executivo, cooperadores, como taes, na execução das leis, sem que sejam adstrictos a essa delegação expressa por via de nomeação régia". (Ib., col. 243, n. ${ }^{\circ}$ ). 
Em tal caso "a delegação do poder central nasce da lei mesma, que enxerta essa delegação, directamente, em um mandato electivo. Excepção é, na verdade; mas basta, para estabelecer a possibilidade legal da generalização. Assim que não ha correlação necessaria entre investidura régia e a delegação de certos poderes extramunicipaes ao chefe da municipalidade". (Ibid). Isto é: chefe da municipalidade continua elle a ser sobre tudo. Nem a investidura régia, nem os poderes extra-municipaes, que, com ella o revestem esse funccionario, lhe alteram o caracter predominante de autoridade primordialmente municipal, convertendo-o em instrumento da coroa, que o nomeia.

$\mathrm{Na}$ Italia o art. 123 da lei communal e provincial trasladou, neste ponto, o systema francez, prescrevendo a electividade geral dos syndicos, nome pelo qual se sabe, designam os italianos esta classe de funccionarios, que, gerindo administrativamente as municipalidades, sobre ellas, simultaneamente, exercitam, em nome do rei, certas funcções de superintendencia e inspecção.

A duplicidade legal dessas funcções está explicitamente consagrada no proprio texto desse acto legislativo, em cujo art. 121 se declara ser o syndico chefe da administração municipal e funccionario do governo, "capo della administrazione communale ed ufficiale del governo". (Luigi Frazzini: Sindaco. Digesto Italiano, bol. XXI, parte $3 .^{\mathrm{a}}$, secc. 1. ${ }^{\mathrm{a}}$, pag. 468, n. $^{\circ} 27$ ).

Funccionario do governo é, "emquanto, pela falta, no municipio, de funccionarios do governo, exerce attribuições, que a elles pertenceriam, se elles existissem, e desempenha funcções a elle directamente assignadas como funccionario governativo". (Ib., p. 469, n. ${ }^{\circ} 28$ ). Fóra dahi, assim como no conselho municipal está o poder deliberativo do municipio, assim no syndico reside o seu poder executivo: "come nel Consiglio stá il potere deliberativo del comune, cosi nel sindaco stá quello attivo ed esecutivo". (Ib., p. 467, n. ${ }^{\circ} 26$ ).

Do modo como se combinam essas duas representações, prevalecendo, entretanto, a da municipalidade e que lhe é 
accessoria, temos outro specimem ainda mais caracteristico, e de casa, no que se dá com o prefeito do distrito federal.

Nomeado por decreto presidencial, esse funccionario, ao mesmo passo que, como mandatario da União, está de vigia, para suspender, com o seu veto, os actos do conselho, quando contrarios aos direitos de outros municipios, aos direitos dos Estados, á constituição, ou ás leis federaes, é, em tudo o mais, o orgam da administração municipal, executando as ordens do conselho, gerindo e governando o districto segundo as suas leis, arrecadando-lhe as rendas, ordenando-lhe as despezas autorizadas, formulando-lhe as propostas de orçamento, provendo-lhe os cargos, prorogando-lhe as leis de meios, quando não votadas em tempo annualmente, convocando extraordinariamente, quando preciso, os legisladores: locaes, e desempenhando-se de todos os outros deveres administrativos, que lhe impõem as leis organicas desta municipalidade, consolidadas pelo dec. de 8 de março de 1904 .

De todos estes casos, onde vemos realizar-se typicamente a coassociação das funcções de agente do governo do Estado com as de chefe da administração da municipalidade, no maire, burgomestre, syndico, ou prefeito, resae, com os traços da mais clara evidencia, a noção de que o caracter essencial a esse cargo, o seu caracter nativo e indelevel, o seu caracter especifico e dominante é o de orgam do governo municipal, onde, por conveniencia do Estado, inserem as leis deste a delegação adventicia de representante dos interesses do governo central na localidade.

Herion de Pansey, depois de repartir as funcções das entidades municipaes em duas classes distintas, as derivantes: do seu mandato local e as originarias da delegação da lei, notando que as primeiras são as funcções municipaes propriamente ditas e as segundas são funcções administrativas, acaba reflectindo: "Os funccionarios municipaes exercem as primeiras como agentes das duas communas e as segundas como agentes da administração geral. A lei, que lhe confere estas ultimas, dellas os poderá desinvestir. As demais são de tal modo inherentes ao poder municipal, que deste não po- 
dem jamais destacar". (Compét., cap. XXIII, - Léon Wodon: Traité des choses publiques, n. ${ }^{\circ}$. pags. 15-16).

Com estas idéas elementares, fundamentaes e imprescritiveis em materia de organização municipal, idéas que constituem, digamos assim, a magna carta universal das instituições de hoje neste assumpto, estaria em flagrante desaccordo a legislação mineira, se, realmente, o prefeito, alli, nos municipios de que se trata, os mais importantes de Minas, estivesse reduzido a "mero intermediario do presidente do Estado".

As suas idéas actuaes não justificam essa versão.

Em verdade o acto que creou a prefeitura da cidade de Minas, o dec. n. ${ }^{\circ} 1.088$, de 29 de dezembro de 1897, referindo-se ao art. $8 .^{\circ}$ da lei n..$^{\circ} 3$, addicional á constituição do Estado, assim se pronunciava, nos arts. $2 .^{\circ}$ e $3 .^{\circ}$ :

"A direcção economica e administrativa da cidade de Minas, nos termos do art. $8 .^{\circ}$ da lei citada, se exerce por meio de funcções deliberativas e executivas. As funcções deliberativas são exercidas, directamente, pelo presidente do Estado, e as executivas se-lo-ão por intermedio de um prefeito de sua livre nomeação".

O que dispunha a lei n. 3 , addicional á constituição do Estado (L. de 17 de dezembro de 1893), invocada no primeiro destes dois artigos, era:

"A direcção economica e administrativa da capital do Estado, denominado Minas, ficará a cargo do Presidente do Estado, emquanto o congresso não deliberar a respeito nos termos da Constituição".

A constituição Mineira, votada em junho de 1891, encerrava, acerca da organisação dos municipios, as idéas mais liberaes. $\mathrm{O}$ seu art. $75, \mathrm{n} .^{\circ} \mathrm{II}$, estatuia que:

“a administração municipal, inteiramente livre e independente em tudo quanto respeita ao seu pe- 
culiar interesse, será exercida, em cada municipio, por um conselho eleito pelo povo, com a denominação da camara municipal".

Esse mesmo artigo, no seu n. ${ }^{\circ}$ VII, determinava que:

“o governo do Estado não poderá intervir em negocios peculiares do municipio senão no caso de perturbação da ordem "publica".

Essas e outras normas, allí exaradas em dezeseis clausulas successivas, formaram "as bases", que o art. 75, nas suas palavras iniciaes, exigia serem "respeitadas" na "lei especial", que, segundo o preceito daquelle texto, "regulará" a organisação dos municipios". E, quando, no art. 30, a constituição mineira, definindo a competencia do congresso do Estado, o incumbiu de "legislar sobre camaras municipaes" (n. ${ }^{\circ}$ ), foi prescrevendo que o fizesse "nos termos dos arts. 75 a $80^{\prime \prime}$.

A lei.$^{\circ} 3$, portanto no seu art. $8 .^{\circ}$, onde se estabeleceu, para o municipio da capital do Estado, um regimen, que absorvia no chefe da administação estadoal todos os poderes municipaes, era, nesta parte, não um acto addicional, mas, pelo contrario, uma derogação radical á constituição mineira. Não se poderia figurar contradicção mais absoluta que a do art. $8^{\circ}$ da lei n. ${ }^{\circ} 3$ com o art. 75 , n..$^{\circ}$ II e VI, da constituição do Estado. Esta firmara o principio da autonomia municipal em toda a sua pureza. Aquella entregava inteiramente o municipio da capital á acção discricionaria do presidente do Estado.

Foi esta formula a que o decreto de creação da prefeitura dessa capital, o dec. n. ${ }^{\circ} 1088$, de 1897, decreto administrativo, desdobrou nos dois artigos já transcriptos, declarando que, nos termos do art. $8 .^{\circ}$ da lei $n .^{\circ} 3$, ao presidente do Estado cabiam, naquella municipalidade, cumulativamente, as funcções exclusivas e as funcções deliberativas, as pri- 
meiras exercidas mediante o prefeito, de sua livre escolha, as segundas pelo chefe do Estado em pessoa.

Dois annos perdurou ainda, intacta, essa aberração que a lei n. $^{\circ} 275$, de 12 de setembro de 1899 , veio modificar, instituindo, pelo seu art. $1 .^{\circ}$, na capital do Estado, um conselho deliberativo, de sete membros, eleitos pelo povo.

Mas essa lei mesma reduziu a competencia do conselho, allí creado, ao voto dos impostos e a fixação das despezas. E' o que dispõe o seu art. $2 .^{\circ}$. E o art. $7 .^{\circ}$, depois de estabelecer que "as funcções executivas do governo local da cidade de Minas continuarão a ser exercidas pelo prefeito, de nomeação do presidente do Estado", accrescenta que a este

“continúa a competir a direcção administrativa da mesma cidade e a regulamentação dos diversos serviços, que lhe forem peculiares, nos termos da lei addicional á constituição, $n .^{\circ} 3$, de 17 de dezembro de 1893".

Dest'arte, circunscrevendo o papel do conselho municipal da metropole mineira ao de uma assembléa meramente orçamentaria, cerceando-lhe todas as demais funcções inherentes á missão dos conselhos municipaes, e consolidando no presidente a dictadura municipal, que sobre aquella cidade lhe ortourgara $o$ art. $8 .^{\circ}$ da lei $n .^{\circ} 3$, contra o disposto no art. 75, n. ${ }^{\text {s }}$ II e IV, da constituição do Estado, - a lei n. ${ }^{\circ} 275$, de 1899, attentava, a um tempo, contra essa constituição e contra a lei addicional $n .^{\circ} 3$, convertendo em regimen permanente e definitivo o que ella, declaradamente, assentara, como anomalo e provisorio, para, "enquanto o congresso não deliberasse a respeito nos termos da constituição mineira".

Quatro annos mais tarde outra reforma da constituição, menos reaccionaria em materia de organisação municipal que a lei $n .^{\circ} 3$, adoptada dez annos antes, produziu a lei $n .^{\circ} 5$, de 13 de agosto de 1903, addicional á constituição do Estado; e, nessa emenda constitucional, o art. $100^{\circ}$ determinava que, assim na capital do Estado, como nos municipios ou districtos 
onde existiam em exploração aguas mineraes, a administração desses districtos ou municipios será confiada a um conselho electivo e a um prefeito nomeado pelo governo.

O $\S 1 .^{\circ}$ desse artigo traça a competencia do conselho electivo, ficando por taxar alli a da prefeitura. Evidente é, porém, que a primeira limitava e determinava a segunda nas suas linhas capitaes, devendo tocar ao prefeito o que alli se não achasse aquinhoado ao conselho electivo.

Deste modo, pois cessava, para a capital do Estado, o regimen instituido pelo art. $7 .^{\circ}$ da lei $n .^{\circ} 275$, de 12 de setembro de 1899, onde, apesar de creado, naquella metropole, pelo dois primeiros artigos desse acto legislativo, um conselho deliberativo de eleição popular, se mantinha ao presidente do Estado "a direcção administrativa da cidade e a regulamentação dos diversos serviços a ella peculiares", materia esta inherente, de sua essencia, á esphera de acção da assembléa allí instituida.

Cessava esse regimen, comquanto a lei . $^{\circ} \mathbf{2 7 5}$, de 1899 , invocasse, no seu art. $7 .^{\circ}$ a lei n. ${ }^{\circ} 3$, cujo art. $8 .^{\circ}$, deixara ao presidente do Estado a direcção economica e administrativa da capital, - cessara digo, não só porque o proprio art. $8 .^{\circ}$ da lei $n .^{\circ} 3$, incumbia o congresso mineiro de dar ao municipio daquella cidade um regimen, que se inspirasse "nos termos da constituição", mas ainda porque, sendo uma lei de reforma constitucional a lei $n .^{\circ} 5$, como o fora a lei $n .^{\circ} 3$, esta, pelo mero facto de ser anterior áquella, se achava por ella revogada.

$\mathrm{E}$, como o que na lei n. $^{\circ} 5$, se dispunha a respeito do municipio da capital, disposto allí estava, egualmente, no mesmo texto do art. $10 .^{\circ}$, em relação aos municipios de aguas mineraes, claro está que, no tocante a estes, como no concernente áquelles, se negavam ao presidente do Estado as funcções deliberativas, isto é, as funcções de legislatura municipal, com que o quizera dotar o dec. n. ${ }^{\circ} 1.088$, de 1897, mitigado, mas ainda, parcialmente, mantido pela lei $n .^{\circ} 275$, de 1899. 
Sendo esta a situação do assumpto perante as leis constitucionaes do Estado, a lei estadual $n .^{\circ} 373$, de 17 de dezembro de 1903, autorizou o governo a instituir, provisoriamente, prefeituras nos municipios de Caldas e Caxambú, observando-se para com elles o regimen estabelecido no dec. $n .^{\circ} \mathbf{1 0 8 8}$, de 29 de dezembro de 1897.

Mas essa lei, neste ponto, era manifestamente inconstitucional, porquanto dava como subxistente o regimen do dec. $n .{ }^{\circ} 1088$, de 1897 , onde se prescrevera que "as funcções deliberativas", no municipio, "são exercidas directamente pelo presidente do Estado", quando a reforma constitucional da lei n..$^{5}$, promulgada em 1903 , entregando a administração, no municipio da capital e nas de aguas mineraes, "a um conselho electivo", com um prefeito nomeado pelo governo, implicitamente varrera da legislação aquelle decreto administrativo, acabando com o systema, que confiava ao presidente do Estado as funcções de legislador local alli acobertadas com o nome de "funcções deliberativas".

Isto mesmo reconhecia, ao que parece, pouco depois, o proprio legislador estadoal; pois, logo no anno subsequente, o congresso do Estado adoptou a lei $n .^{\circ} 396$, de 23 de dezembro de 1904, onde, regulando-se a condição dos municipios, o que dizia respeito a autorização conferida ao governo na lei n. 373 , de 1903 , a que me acabo de referir, mandava submetter esses municipios, não ao regimen, a que essa lei os submettera, do dec. n. ${ }^{\circ} 1088$, de 1897 , que enfeixa nas mãos do presidente do Estado todas as funcções, executivas ou deliberativas, mas ao regimen da lei $n .^{\circ} 275$, de 1899 , que entregava as principaes funcções deliberativas ás camaras municipaes.

E', entretanto, nesse dec. n. ${ }^{\circ} 1088$, de 1897 , tres vezes citado no parecer do eximio jurisconsulto, a quem se deve a resposta á consulta do Conselho de Poços de Caldas, é ahi que elle assenta a base capital das suas conclusões mais importantes, acabando por transcrever integralmente o art. 3. ${ }^{\circ}$ ( - no original ha uma observação no fim da pagina que é: "Na copia que me remetteu, desse parecer, o n. ${ }^{\circ}$ do art. está, 
por equivoco, 2, em vez de 3" -), desse decreto, segundo o qual, nos municipios de que se trata,

\begin{abstract}
"as funcções deliberativas são exercidas directamente pelo presidente do Estado, e as executivas sel-o-ão por intermedio de um prefeito de sua livre nomeação".
\end{abstract}

Mas, se o systema do dec. n.. 1088 , subsistisse, delle não se deduzia sómente que o prefeito, nessas municipalidades, é meramente um funccionario estadoal, simples intermediario do presidente do Estado: seguir-se-ia, egualmente, que, nesses municipios, as funcções deliberativas são directamente exercidas tambem pelo presidente do Estado.

Ora, o dec. n. ${ }^{\circ} 1088$, de 1897 , é um acto puramente $a d m i-$ nistrativo do governo de Minas; e a esse acto succederam, primeiramente, a lei constitucional $n .^{\circ} 5$, de agosto de 1903 , que, nos municipios de aguas mineraes, como no da capital, instituiam para as funcções deliberativas, a competencia dos conselhos electivos, e, mais tarde, a lei ordinaria $n .^{\circ} 396$, de dezembro de 1904, que, reconhecendo como da competencia dessas camaras municipaes as funcções definidas na lei n. ${ }^{\circ} 275$, de 1899 , ipso facto attribuia a essas camaras as mais relevantes funcções deliberativas do governo municipal, que essa lei, no seu art. 3. ${ }^{\circ}$, reserva aos conselhos electivos.

O preceito do dec. n..$^{\circ} 1088$, portanto, no seu art. $3 .^{\circ}$, tres vezes invocado no parecer de que lamento divergir, soffreu, pelo menos duas vezes, a acção revogatoria de duas leis de ordem superior: a reforma constitucional de 1903, e a lei ordinaria de 1904.

Digo "pelo menos duas vezes"; porque, em bôa conta, esse numero se deve elevar a tres, Com effeito, posterior ao dec. $n .^{\circ} 1088$, de 1897 , já era a lei $n .^{\circ} 275$, de 1899 , anterior á reforma constitucional de 1903, lei na qual já se desfalcavam do poder attribuido ao presidente as attribuições concernentes á receita e despeza municipal, desde então comettidas, na capital do Estado, ao conselho electivo. 
De sorte que essa disposição do dec. n. 1088 , ainda agora adduzido com tamanha estima e confiança para justificar o systema da concentração de todos os poderes municipaes na presidencia do Estado, não teve, realmente, na legislação Mineira, senão uma existencia ephemera de menos de dois annos, e, inconciliavel, como é, com tres leis estadoaes, de 1899, 1903 e 1904, que acabo de apontar, tres vezes está por ellas revogada.

Quando, mesmo, porem, nenhum desses tres actos legislativos tivesse havido, bastariam para abrogar o celebre artigo, de um acto puramente administrativo, as disposições do dec. n. $^{\circ} 1.777$, de 30 de dezembro de 1904 , decreto administrativo tambem, que approvou, o regulamento das prefeituras de Caxambú e Poços de Caldas.

Ao passo, com effeito, que, no dec. n..$^{\circ} 1088$, de 1897, o art. n..$^{\circ}$, a que se atem o parecer do eminente advogado, declara que "as funcções deliberativas são exercidas directamente pelo presidente do Estado", os arts. $20^{\circ}$ e $3 .^{\circ}$ do dec. n. $^{\circ} 1.777$, pelo contrario, inspirando-se na lei $n .^{\circ} 5$, de 1903, e na lei n. ${ }^{\circ}$ 396, de 1904, dizem que, em Caxambú e em Poços de Caldas, a administração local será exercida por um conselho electivo, designado pelo nome de conselho deliberativo, e um prefeito, competindo a este as funç̧ões de caracter executivo e áquelle ás de caracter deliberativo.

Logo, revogado está, categoricamente, pelos dois artigos iniciaes do dec. $n .^{\circ} 1.777,3 .^{\circ}$ art. do dec. $n .^{\circ} 1088$, transferindo-se para os conselhos electivos as funcções deliberativas, que no ultimo desses dois actos, primeiro na ordem chronologica, estavam reservadas ao governo do Estado.

Longe de se oppor a esta conclusão, o disposto no art. 31 do dec. n. ${ }^{\circ}$ 1.777, ainda a vem corroborar; pois, mandando elle observar, nas leis que ennumera, "tudo quanto não estiver prevenido neste decreto, nem for contrario ao que elle estatue", nega, evidentemente, vigor a esses actos, na parte em que elles attribuem ao presidente do Estado funcções deliberativas da administração municipal, consignadas pelo dec. $n .^{\circ} 1.777$, aos conselhos electivos, ou reduzem 
a situação do prefeito a menos do que nesse decreto se acha regulado.

Ora a formula do art. $3 .^{\circ}$ do dec. n. ${ }^{\circ} 1088$, assim como cessou de ser admittida nas leis posteriores quanto á abrogação das funcções deliberativas pela presidencia do Estado, assim tambem não encontrou na legislação ulterior nenhum acto que a acceitasse no seu segundo membro, o em que o texto qualifica as funcções executivas como attribuições egualmente do chefe do Estado, exercidas "por intermedio" de um prefeito, fazendo, assim, dessa autoridade um funccionario estadoal, mero intermediario do presidente, na linguagem do parecer, que admiro como douto, mas não como justo.

Nem a lei addiccional n. ${ }^{\circ}$, de 1903 , nem a lei n. 396 , de 1904, nem o dec. n. 1.777 , do mesmo anno repetem as expressões do dec. n. ${ }^{\circ} 1.088$, de 1897 , declarando que "o presidente exerce as funcções executivas por intermedio do prefeito de sua nomeação".

Todos estes actos, successivos ao dec. n. ${ }^{\circ}$ 1088, de 1897, estatuem que o prefeito é de nomeação do presidente, em cuja dependencia o collocam a certos respeitos. Mas nenhum estende essa dependencia a todas as suas funcções, ou determina, explicita nem implicitamente, que o prefeito será o vehiculo da presidencia do Estado no exercicio do poder executivo municipal, a ella reservado como ramo da sua autoridade.

Que, no mechanismo da organização imposta, pelo dec. n. ${ }^{\circ}$ 1.777, de 1904, ás prefeituras de Caxambú e Poços de Caldas, o prefeito, em muitas das suas attribuições, representa o governo do Estado, - não ha contestal-o, nem interesse poderia haver em que se contestasse. E' o que se dá, na França, na Belgica, na Hollanda, na Italia, em outros paizes, com os prefeitos, os maires, os syndicos, os burgomestres, nomeados ou não pelo governo, mas investidos em certas funcções de representação do governo geral e, como taes, sob esse aspecto, seus representantes, seus orgams. 
Isto, porem, não tolhe que, ao mesmo tempo, e principalmente, sejam funccionarios da administração local, funccionarios municipaes, cuja autoridade, por este lado, independente do governo central, se desenvolve livremente, no execicio de um mandato, que da lei decorre, e em cuja autonomia ella o escuda.

E o que se vê no art. 17 do dec. n. $^{\circ}$ 1.777, onde se regulam as funcções do prefeito de Poços. A um relance d'olhos, immediatamente se percebe como alli se separam as duas faces da sua autoridade. Muitos dos trinta e cinco paragraphos alli dispostos caracterizam o papel do agente da presidencia do Estado. Nesse numero sobresaem os $\S \S 9 .^{\circ}$, 25 a 31 e 34 e 35 , cujos objectos giram no circulo de interesses mais ou menos geraes.

Mas em quasi todas as outras clausulas desse artigo a autoridade que se define, que se commete, que se afigura ao prefeito, é necessariamente, mais ou menos caracteristicamente municipal, e se exercita com a liberdade legal de um poder proprio, sob o contraste, não do governo do Estado, mas da opinião da municipalidade, seus eleitos, seu conselho deliberativo,

Nesta categoria estão:

1..$^{\circ}$ o dever de apresentar ao conselho, em cada uma das suas sessões ordinarias um relatorio da administação municipal $\left(\& 10^{\circ}\right)$;

$\left.2 .^{\circ}\right)$ o de executar as leis municipais $\left(\S 2 .^{\circ}\right)$;

3. ) o de lhes dar publicidade $\left(\S 3 .^{\circ}\right)$;

4. $)$ o de apresentar annualmente, ao conselho o projecto de orçamento $\left(\S 4 .^{\circ}\right)$;

5. ) o de publicar, em cada exercicio, o seu orçamento $\left(\S 5 . .^{\circ}\right)$;

6. $)$ o de arrecadar as rendas municipaes $\left(\S 6 .^{\circ}\right)$;

$\left.7 .^{\circ}\right)$ o de ordenar e pagar as despezas orçadas $\left(\S 7 .^{\circ}\right)$;

$\left.8^{\circ}\right)$ o de publicar os balancetes da receita e despeza $\left(\S 8 .^{\circ}\right)$; 
9. ) o de nomear, suspender, licenciar, e demittir os: empregados municipaes ( $\left.\S 11 .^{\circ}\right)$;

$\left.100^{\circ}\right)$ o de inspeccionar e dirigir os serviços municipaes $\left(\S 12.0^{\circ}\right)$;

11..$^{\circ}$ o de convocar extraordinariamente o conselho, quando o houver por bem $\left(\S 13.0^{\circ}\right)$;

$\left.12 .^{\circ}\right)$ o de dirigir a policia municipal $\left(\S 15 .^{\circ}\right)$ e o de impor multas aos infractores das leis municipaes $\left(\S 16 .^{\circ}\right)$;

13..$^{\circ}$ o de representar o conselho em juizo, ou fóra delle, $\left(\S 17.0^{\circ}\right)$;

$\left.14 . .^{\circ}\right)$ o de prover á hygiene publica $\left(\S \S 18 .^{\circ}\right.$ a $\left.21 .^{\circ}\right)$;

$\left.15 .^{\circ}\right)$ o de velar pelos proprios municipaes. ( $\left.\S 22 .^{\circ}\right)$;

16..$^{\circ}$ o de inspeccionar as construcções particulares de accordo com as posturas municipaes $\left(\S 23 .^{\circ}\right)$;

17..$^{\circ}$ o de prover, por todos os meios, á tranquilidade, saúde, segurança, e commodidade geral do logar (§ 24. $)$;

18..$^{\circ}$ o de superintender na execução das obras e contractos municipaes $\left(\S 32 .^{\circ}\right)$;

Ora essas funcções, todas ellas, sem excepção alguma, não exerce o prefeito, não lhe incumbem a elle por delegação ou em representação do governo do Estado. São attribuições, que the pertencem como chefe da administração, que só da sua posição nesta lhe advem a elle, e que, portanto, o caracterizam como funccionario essencialmente. eminentemente municipal.

E' o que ensinam unanimemente as licções, as leis, os livros de direito administrativo em toda a parte.

Não é "cume ufficiale del governo", mas quale capo dell'amministrazione municipale", que os syndicos, na Italia, procedem á convocação dos conselhos municipaes, funccionam nas suas relações com estes conselhos, executam-lhes. as deliberações, celebram os contractos estipulados em nome da municipalidade, entendem na observancia das leis e regulamentos locaes, representam a communa em juizo, supe- 
rintendem nas instituições e representações do municipio, e exercem sobre os funccionarios o ascendente administrativo. (Digesto Ital., loc. cit., p. $467-9$, nos., $26-29$, pg. 470, n. $^{\circ}$ 31 , p. 471, n. ${ }^{\circ} 37$, p. 474, n. $^{\circ} 45$, pg. $475-6$, n. $49-50$, pg. 477 , n. $\left.{ }^{\circ} 54\right)$;

Similhantemente, em França (como na Belgica) os mestres, depois de registarem "as attribuições do maire considerado como representante do Estado", classificam-lhe as attribuições "emquanto orgam executivo da communa", contemplando entre estas a organização dos seviços munipaes, a policia dos funccionarios da municipalidade, a policia municipal (que abrange a ordem publica, a segurança, a salubridade), a policia do dominio publico local (onde se comprehendem a viação, as construcções, os cemiterios), a administração do dominio privado municipal, a execução das decisões do conselho, cumprindo o orçamento, celebrando os contractos, representando nos tribunaes a communidade, superintendendo-lhe as obras, assegurando por todos os meios a observancia ás resoluções do corpo deliberativo. (HAURION: Op. cit., pg. 306-308).

Numa palavra: em todos os actos, mediante os quaes se exercem as funcções proprias do poder municipal, o funccionario, que a ellas preside, é funccionario da municipalidade, e não do governo. Ora "funcções proprias ao poder municipal são todas as que interessam directa e peculiarmente á communa, que os funccionarios municipaes representam". HENRION DE PANSEY: Loc. cit.).

A concepção de um systema de municipalidades, onde as funcções deliberativas pertençam ao chefe do Estado, e as executivas se commentam a um mero intermediario do chefe do Estado, como queria, em Minas, o art. 3..$^{\circ}$ do dec. 1.088, de 1897, é uma aberração barbara, um barbarismo politico, de não sei onde se encontrarão antecedencias nos paizes de governo medianamente constitucional.

A constituição do imperio, nos art. 167 e 168, assegura a todas as cidades e villas a sua propria administração por meio de camaras, a quem reservava "o governo municipal", 
determinando que essas camaras seriam electivas e designando entre os eleitos, pela maioria dos votos populares, o seu presidente.

A lei de $1 .^{\circ}$ de outubro de 1828 realisou com lealdade o pensamento constitucional; e, durante o antigo regimen, até os magnatas da escola conservadora, os seus pontifices mais orthodoxos reconheceram na autonomia dos municipios, contida na sua orbita natural, um elemento substancial e impreterivel da ordem juridica do Estado.

Os juristas da republica devem avivar as suas idéas constitucionaes e acrysolar a sua educação democratica, bem tresmalhada, relendo as paginas do Marquez de S. Vicente, onde elle resumia assim as noções liberaes, que os conservadores mais timoratos não se atreviam a desapprovar:

"A natureza do poder municipal revela quaes devam ser as suas attribuições essenciaes. Tudo quanto respeita especialmente á sociedade local, tudo quanto não for de interesse provincial ou geral, deve ser attribuido ao conselho da familia municipal". E' justo e conveniente que essa associação se governe como melhor julgar, em tudo quanto essa liberdade não offender os outros municipios ou os interesses do Estado....

"Quando as attribuições municipaes são insignificantes, quando as camaras não podem prestar bons serviços, os cidadãos mais notaveis fazem de onerar-se com o cargo inutil de vereador, e a instituição cae em desprezo e nullidade... "Direito Publico Brasileiro, pag. 316, n. ${ }^{\circ} 449$.

Nessa região, onde o estadista conservador proclama o direito da colletividade local a se governar a si mesma, elle proprio nota que se incluem necessariamente dois elementos organicos, ambos indispensaveis á vida normal da localidade: o poder legislativo e poder administrativo, um e outro municipaes. 
“A instituiçâo municipal, diz elle,

"tem duas partes distinctas: a primeira é a que delibera, que vota, que recebe e examina as contas, é o conselho e como que poder legislativo local; a segunda, a que executa, que presta as contas, é uma autoridade que emana do poder administrativo." (Ib., p. 318, n. ${ }^{\circ}$ 450).

$\mathrm{E}$, quer na parte onde legisla, quer na em que executa, entendiam os conselheiros conservadores da corôa que a sociedade municipal se ha-de "governar a si mesma, como melhor julgar".

Ora estes rudimentos da liberdade popular, estes primeiros principios de toda a democracia não cairam com o cair do antigo regimen. Não. Tiveram, pelo contrario, na sua carta fundamental, a solemne consagração, que lhes deu a constituição de 1891, dedicando aos direitos "Do Municipio" um titulo especial, exclusivo, onde, com uma brevidade lapidar, mas assaz incisiva e ampla, na sua clareza, para salvar a tradição democratica, o capital adquirido em materia de franquias municipaes, determinou, no seu unico art., o art. 68:

"Os estados organizar-se-ão de forma que fique assegurada a autonomia dos municipios, em tudo quanto respeite ao seu peculiar interesse".

Com o vigor desta fórmula, notavelmente rigida collidiria materialmente qualquer acto, que, nos regulamentos, leis ou constituições estadoaes, violasse a autonomia dos municipios em' algum assumpto do seu peculiar interesse, quanto mais um divorcio escandaloso desse preceito supremo, qual o que, em Minas, tentou o dec. n..$^{\circ} 1083$, no seu art. 3. que eliminava pela raiz a autonomia municipal, estatuindo que, em certas municipalidades, "as funcções deliberativas são exercidas directamente pelo presidente do Estado, e as 
executivas sel-o-ão por intermedio de um prefeito de sua livre nomeação".

Esta disposição, pois, - como todas as que, menos destemperadas, se resentem do seu parentesco, na legislação mineira - deve considerar-se morta de nascença, por clamorosamente offensiva da constituição nacional; de modo que não seria licito invocal-a seriamente, num debate juridico, em apoio de qualquer solução.

Nas nossas municipalidades toda a funcção deliberativa ou executiva é, necessariamente, municipal, e necessariamente municipal a funcção executiva ou administrativa.

Não se infere dahi que o orgam da administração municipal, em certos municipios, por conveniencia do Estado, não possa receber, tambem, um mandato do governo deste, em relação a certos e determinados assumptos, nos quaes os interesses geraes concorrem com os da localidade, e, sem prejuizo destes, convenha terem alli um guarda autorizado.

Essas materias, de natureza evidentemente excepcional em relação ás que compõem a alçada normal do governo da municipalidade, têm, portanto, de ser, com muita nitidez, taxadas, especificadas, individuadas, como, na hypothese, o são pelo dec. 1777 , de 1904, cujo art. 17 as particulariza e res tringe nos $\S \S 25$ a 31,33 a 35.

A respeito dessas attribuições, o prefeito, como alli se chama o chefe do serviço administrativo na localidade, funcciona como intermediario do presidente do estado, seu vigia, seu representante. Em tudo o mais, e, por conseguinte, no principal da sua tarefa, é um poder municipal, é a encarnação da autonomia do municipio na execução das suas leis e na administração dos seus interesses.

Tenho assim respondido ao quesito $e$, ao quinto quesito da consulta, que na ordem natural das questões propostas, é o primeiro: o prefeito não é um méro intermediario do presidente; é, tambem, um poder eminentemente municipal.

Intermediario do presidente do estado, só o é, só é unicamente, nas funcções de conveniencia estadoal, que não sejam, por sua natureza, peculiarmente municipaes. 
A primeira consequencia que daqui se desdobra, é a que interessa ao quesito $a$, o primeiro quesito.

O prefeito, quando contracta, recebe ou paga, quando adquire, conserva, applica ou gere bens commettidos á sua administração, quando obra, em summa, como depositario do patrimonio confiado á sua guarda, representa a municipalidade, como administrador geral, de cujos haveres, compromissos e responsabilidades se acha constituido, no seu caracter legal de chefe da sua administração.

A sua competencia nesa qualidade se estende a todos os assumptos definidos na lei n. ${ }^{\circ}$, de 13 de agosto de 1903, art. $10 .^{\circ}$.

Verdade seja que, nesse texto, o $\S 20^{\circ}$ estabelece que "os recursos e auxilios fornecidos pelo Estado não ficarão sujeitos á inspecção e deliberação dos conselhos, mas serão applicados pelo prefeito, na forma das leis e regulamentos do Estado, a cujo governo elle prestará contas".

Esta clausula, porem, está visivelmente subordinada ao principio transparente e claro no paragrapho anterior, o $\S 10^{\circ}$ onde se abrangem na competencia dos organs da municipalidade todos "os serviços de interesse puramente local".

Ora na exposição da consulta se adverte que as obras e melhoramentos, aos quaes se destinaram, e nos quaes se empregaram os 1.226:000\$rs., fornecidos pelo governo de Minas, ao municipio de Poços de Caldas, foram, sem excepção, melhoramentos e obras de caracter municipal: nivelamento e macadamização de ruas, canalisação de corregos, ajardinamento de praças, arborização da cidade, construcção de mercados e matadouros, edificação da casa da Prefeitura, melhoramentos nos serviços de aguas, no de exgottos e outros similhantes.

Pôr em duvida a natureza puramente municipal de taes applicações e acquisições fôra, realmente, desconhecer, esquecer, ou inverter o que, na doutrina juridica e constitucio- 
nal, passou, entre nós, em julgado ha noventa annos, desde a lei de $1 .^{\circ}$ de outubro de 1828 , matriz de toda a legislação municipal no Brasil.

Obvio é, por conseguinte, que, ao receber e dispender em taes obras as sommas, com que para ellas contribuiu o Thesouro do Estado, o papel dominante nos actos do prefeito de Poços de Caldas foi o de administrador legal dessa municipalidade, ou, nos termos da lei $n .^{\circ} 5$, de 1903, art. $10 .^{\circ}, \S 1 .^{\circ}$, o de gestor "dos serviços de interesse puramente local".

Os factos mostram que de outro modo não pensava, nem pensa o governo do Estado. A prova, temol-a concludente nas circunstancias de que essas obras se acham inteiramente na posse da municipalidade, de que esta lhe tem percebido totalmente as rendas, e de que, graças a estas, a receita municipal cresceu, em quatro annos, cento e cincoenta por cento, sem que o governo estadoal reclamasse jamais nem comparticipação em taes rendimentos, nem juros do capital, subministrado por elle, de que resultou ao municipio esta prosperidade.

Se a melhor, a mais segura interpretação da indole de um acto juridico, é a sua interpretação praticamente authentica, a que lhe dão as proprias partes, no modo como o executam, e nas consequencias que delle tiram, está visto que a administração mineira forneceu essas quantias ao municipio de Caldas a titulo de mera liberalidade.

$O$ governo de Minas, deixando que aquellas quantias tivessem o destino que tiveram, que se empregassem todas em obras necessarias e inalienavelmente municipaes, conveio, da maneira mais concludente, em que esse capital se incorporasse de um modo cabal e definitivo no patrimonio da municipalidade, renunciando assim a quaesquer direitos de proprietario sobre os bens, que da applicação desse dinheiro provieram.

Outrosim, abstendo-se de convencionar por alguma forma o reembolso daquelle capital, de estipular o premio do seu aluguel, ou, siquer, os termos da sua amortização gradativa, exprimiu a vontade manifesta de o não emprestar, de o 
não rehaver, nem lhe perceber o interesse, contentando-se, como compensação do seu sacrificio, com' o proveito geral, adveniente a Minas, do desenvolvimento de um grande centro de attracção e de um foco importante de cultura no meio do Estado.

Não foi, pois, um mututo, um emprestimo, o que o governo mineiro fez ao municipio de Poços de Caldas. Tampouco se poderá dizer que, com isso, adquiriu bens, cujo dominio lhe pertença, e cuja administração exerça por meio de prefeito como seu procurador e feitor. Foi, simplesmente um auxilio gratuito, com que, concorrendo para o desenvolvimento da preciosidade que aquelle municipio representa, concorreu para a expansão da riqueza do Estado, seu povoamento, sua civilização, seu renome, á similhança do que com Santos fez o governo de São Paulo, e, com o Rio de Janeiro, o da União, prosperando essas duas capitaes, á custa de innumeras despezas do Thesouro Federal e do Thesouro paulista, com obras extraordinarias, que se municipalizaram, que se absorveram no patrimonio das duas cidades, sem se constituir nem uma nem outra na obrigação de pagar esses melhoramentos á fazenda estadoal, ou á fazenda nacional, nem ter de lhes reembolsar o capital, em que elles importaram.

Logo, recebendo essas quantias do Thesouro do Estado para melhoramentos caracteristicamente municipaes, e gastando-as nesses melhoramentos, o prefeito de Poços de Caldas adquiriu para este municipio, e administrou o patrimonio desse municipio, em virtude, unicamente; dos seus poderes legaes como representante da municipalidade, como cabeça da sua administração.

Logo, ainda, se da execução desses melhoramentos resultou um deficit, um passivo, uma divida verificada, seja de quanto for, esse debito não foi contrahido pelo governo do Estado, mas pelo da municipalidade.

Logo, emfim, a esta é que incumbe a responsabilidade por essa obrigação, que só ella tem o encargo de solver. 
Ficam assim respondidos os quesitos $a$ e $f$, a saber, o primeiro e o sexto.

\section{III}

A constituição de Minas Geraes, no art. 79, estabelece que

"em seus orçamentos as camaras municipaes consignarão os fundos necessarios para amortização e juros dos emprestimos, que contrahirem".

accrescentando ( $\S$ unico) :

"Não serão contrahidos novos emprestimos quando o encargo dos existentes consumir a quarta parte da renda municipal".

Desta 'disposição constitucional decorre que nenhum municipio mineiro pode contrahir um emprestimo, sem que a sua camara municipal seja ouvida e delibere, antes e depois da operação:

antes da operação, afim de a autorizar, ou não, examinando se a renda municipal ainda lhe comporta os encargos dentro dos limites fixados pelo art. 79 , § unico, do texto constitucional;

depois da operação, afim de examinar o determinado no art. 79, principio, da lei constitucional, consignando, immediatamente, os fundos necessarios á amortização e aos juros do mútuo contrahido.

$A$ isto accresce que, em sequencia a esse artigo, o art. 80 da constituição mineira estatue:

" $O$ congresso ou o governo, em suas leis ou regulamentos, não poderá onerar as camaras municipaes com despezas de qualquer ordem, sem decretar fundos, ou abrir desde logo verba para esse fim." 
Quer isto dizer que não será licito ao governo do Estado, por seus regulamentos ou leis (e, conseguintemente, porquaesquer outros actos seus), onerar as municipalidades com gravames pecuniarios de qualquer natureza.

Destas tres prescripções constitucionaes, encerradas nos nos artigos 79 e 80, se conclue:

1.') que desembolsando com obras municipaes no municipio de Poços de Caldas os 1.226 contos, que desembolsou, o governo de Bello Horizonte, em quem se não pode admittir ignorancia da constituição do Estado, assim obrou com a sciencia e consciencia de que dispendia por sua conta, e não adquiria, por essa despeza, direitos de credor contra aquella municipalidade;

2..$^{\circ}$ que, não se tendo effectuado esses gastos com audiencia do conselho municipal de Poços de Caldas, não se pode considerar que esse municipio houvesse contrahido, para com o Estado, responsabilidade alguma pela acquisição desses melhoramentos;

3. ${ }^{\circ}$ que, não tendo contrahido taes vinculos previamente, não se pode tambem suppor que os acceitasse depois, ratificando responsabilidades assumidas em seu nome, uma vez que, nos quatro annos decorridos, não votou nunca, nos seus orçamentos, os meios necessarios ao serviço dos seus juros e amortização.

Fica, assim, respondido o quesito $c$, o terceiro na serie da consulta; o governo não é credor do municipio pelos auxilios com que concorreu para os melhoramentos de Poços.

\section{IV}

Desde que os desembolsos do governo estadoal com taes obras têm o caracter de auxilio por elle espontaneamente liberalizados áquella municipalidade;

Desde que, em segundo logar, taes auxilios se não deram como emprestimo delle a ella; 
Desde que, emfim, esses auxilios se consumiram em obras de natureza essencialmente municipal:

Claro está que os melhoramentos obtidos á custa desses auxilios em beneficio da municipalidade, entregues á sua administração, deixados em sua posse, incluidos indiscriminadamente entre as fontes da sua receita, foram creados como elementos do patrimonio municipal, e a elle pertencem.

Assim respondo ao quarto quesito, assignalado com a letra $d$, no questionario.

\section{$\mathbf{v}$}

Com a indicação da letra $g$ (setimo quesito) alli se pergunta, em seguida, "se, dada a hypothese de ser o prefeito um preposto ou intermediario do presidente do Estado, o municipio, pagando as dividas por elle contrahidas, fica, ou não, subrogrado nos direitos dos credores contra o Estado".

Não ha, creio eu, utilidade na resposta, desde que o prefeito não é, nas funcções relativas ao caso, intermediario ou preposto do governo estadoal. Mas, já que se faz hypotheticamente a pergunta, vá com a mesma feição a resposta.

Em regra, até hoje entre nós,

"um terceiro, que paga pelo devedor, adquire contra este o mesmo direito, que tinha o credor, ainda que este não lhe faça expressa cedencia do seu direito". C. TELLES: Dig. Port., tom. I, n. 1097).

Portanto,

"o credor que recebe de um terceiro o pagamento de sua divida, entende-se subrogal-o em todos os seus direitos, ainda que não lhe faça cedencia dos mesmos". FELICIO DOS SANTOS : Proj. do Cod. Civ. Bras., art. 485 - COELHO RODRIGUES : Prof. Cod. Civ. Bras., art. 529). 
Opiniões ha, que não admittem a subrogação legal com essa generalidade. Mas essas mesmas reconhecem até a terceiro não interessado, que pagar a divida em seu proprio nome, o direito ao reembolso do que houver pago. (TEIX. DE FREITAS: Esboço, art. 1037 - Proj. do Cod. Civ. Adot. na Cam. dos Dep., arts. 933, 934, 988).

Assim, na hypothese de ser o prefeito mero intermediario do presidente do Estado, o que se daria, pagando o erario municipal dividas por aquelles contrahidas, era que o municipio, subrogado, ou não, nos direitos creditorios, tinha, pelo menos, o de haver da fazenda estadoal, devedora cujo debito houvesse resgatado, a importancia do que por elle tinha pago.

Alem disso, estaria nas mãos do municipio estabelecer, se quizesse, a subrogação convencionalmente, fazendo que os credores, cujas contas saldasse, lhe transmittissem, na quitação, todos os seus direitos contra o Estado devedor. (Proj. do Cod. Civ. Bras. da Cam. dos Dep., art. 989, n.० I. MENDONÇA: Obrigaç. 2. ${ }^{\mathrm{a}}$ ed. Vol. I, n..$^{\circ} 321$, pag. 567).

\section{VI}

Aos quesitos $b$ e $h$ (segundo e oitavo) da consulta.

As questões de responsabilidade e solidariedade, por dividas proprias ou alheias, mediante contracto, delicto ou quasi-delicto, pertencem á materia das obrigações, que, em todos os codigos e legislações, em todas as jurisprudencias e systemas do mundo, constituem um dos ramos do direito civil.

Nessa esphera entra, e radicalmente, a lei mineira $n .^{\circ} 2$, de 14 de setembro de 1891 , na qual se declaram solidariamente responsaveis para com os credores os vereadores, que votarem despezas resolvidas sem credito no orçamento, e se determina que, em taes casos, os serviços, obras ou fornecimentos realisados reverterão em beneficio gratuito da camara, nome pelo qual esse acto legislativo, com impropriedade indesculpavel, designa o municipio. (Art. 84). 
Penetrando nessa região delicada e espinhosa do direito civil, essa lei estadoal o faz com o desprezo dos mais sagrados principios de equidade e honestidade universalmente reconhecidos no direito civil, legitimando, em beneficio das municipalidades, a justiça do confisco, ou do enriquecimento sem causa, contra a noção, immemorial e correntissima no mundo inteiro, de que "Jure naturæ æquum est neminem cum alterius detrimento et injuria fieri locupletiorem". (Fr. 206 D., de reg. juris, XVII).

Ora de legislar sobre o direito civil a faculdade " compete privativamente ao congresso nacional". E' o que, cathegoricamente e sem excepção nem reserva alguma, para todo o territorio da republica, estatue, no art. $34, n .0^{\circ} 25$, a constituição brasileira.

A lei $n .^{\circ} 2$, de 1891 (14 de setembro), portanto, ataca abertamente as nossas instituições constitucionaes, usurpando, sem cerimonia, uma das funcções mais graves, mais altas, mais necessarias do congresso nacional: a que nos garante, em toda a extensão do territorio brasileiro, a unidade legal do direito civil. Irrita e nenhuma é, juridicamente, essa lei, podendo a sua nullidade ser arguida, e devendo ser proclamada, assim nos tribunaes da União, como nos do Estado, toda a vez que contra alguem se invoque esse acto legislativo mineiro.

Mas, quando tal lei subxistisse, não seria invocavel na especie, onde se cogita, não de autorizar despezas, mas de habilitar o prefeito a concluir um emprestimo para solução de debitos legitimamente contrahidos e, pois, de despezas virtualmente feitas.

A constituição de Minas Geraes distingue nitidamente emprestimos de despezas, incumbindo, no art. $30.0^{\circ}, .^{\circ} 2$, o congresso estadoal de fixar as despezas do Estado, e dandolhe, na clausula 18. ${ }^{\mathrm{a}}$ desse mesmo artigo, a competencia para "autorizar o presidente a contrahir emprestimos e fazer outras operaçôes de credito".

E' o que se observa, egualmente, no art. 34 da constituição da Republica, onde na clausula 2. ${ }^{a}$, se estabelece a 
competencia do Congresso Nacional, para "autorizar o poder executivo a contrahir emprestimos, e fazer outras operações de credito", depois de já lhe haver consagrado, na clausula $1 .^{\mathrm{a}}$, a competencia de regular a despeza".

Claro está, portanto, que de emprestimos não trata a lei n. $^{\circ}$, quando se refere a despezas.

Demais a lei $n .^{\circ} 2$ já se acha interpretada, pelo proprio governo do Estado, em sentido contrario ao que ora se lhe quer atribuir, no dec. n. 1.777 , de 30 de dezembro de 1904 , art. 12.

Ahi, positivamente, se declara:

"Salvo proposta do prefeito, nenhuma despeza poderá ser votada, sem que haja verba no orçamento para o seu custeio".

As duas ultimas orações do periodo condensam toda a materia da lei $n .^{\circ} 2$, a que a oração inicial põe a resalva subtendida nos motivos que determinaram o legislador.

Basta uma transposição grammatical do tópico, para se lhe ver sobresair em relevo o pensamento:

"Nenhuma despeza poderá ser votada, sem que haja verba no orçamento para o seu custeio" (Lei n..$^{2}$, de 1891, art. 84), "salvo proposta do prefeito".

Isto é:

Poderá ser votada, sem que haja verba no orcamento para o seu custeio, a despeza, sobre que houver proposta do prefeito.

0 art. 12 do dec. 1.777, de 30 de dezembro de 1904, dando a intelligencia official ao art. 84 de lei $n .^{\circ} 2$, de (no original está 1901, porém, em tinta differente está corrigido para 1891 ?), responde litteralmente as duvidas, que suscitaram os dois quesitos, com que agora me occupo. A restricção, que prohibe aos vereadores resolverem despezas, para as quaes 
não haja credito no orçamento, exceptua os casos, em que as despezas forem solicitadas pelo prefeito.

Obvios são os motivos da interdicção e da excepção. Receiou o legislador, esclarecido pela experiencia, em materia de despeza publicas, os excessos inherentes á ausencia de responsabilidade pratica nas resoluções collectivas dos corpos deliberantes e os desmandos communs á liberdade individual da iniciativa nos seus membros. Mas viu na intervenção do prefeito, na sua iniciativa altamente responsavel, nas suas condições de mediador plastico entre a municipalidade e o governo do Estado, resguardo e seguro cabal contra esses riscos.

Isto posto, responderei:

1. $)$ A disposição da lei n. ${ }^{\circ} 2$, art. 84 e seus paragraphos, contêm materia de evidente direito civil, e, como tal, incorre, ante a constituição do paiz, no vicio flagrante de nullidade.

\section{M a s}

2. ${ }^{\circ}$ Essa norma, restrictiva ás autorizações para despezas, não se estende ás que respeitam á celebração de emprestimos; que é o de que se trata.

Quando, porem, abrangesse os emprestimos,

3.0) Desde que se trata de uma operação proposta pelo prefeito, não se lhe applica o disposto no art. 84 da lei n..$^{2}$.

\section{Conseguintemente,}

4..$^{\circ}$ Admittida, ou não, a subsistencia constitucional desse texto, reconhecida, ou não, a sua applicabilidade geral ás autorizações para a conclusão de emprestimos municipaes, não ha meio, em direito, de sujeitar á responsabilidade pessoal e solidaria da lei $n .^{\circ} 2$, art. 84, os conselheiros, cujo voto autorizar a medida solicitada pela prefeitura.

Muito pelo contrario, a meu ver, 
5. ) Reconhecendo o conselho o passivo demonstrado, e facultando os recursos para a sua liquidação, o que dahi lhe provirá, é consolidar ainda com mais segurança os direitos do municipio á posse e senhorio dos melhoramentos e obras accrescidas ao patrimonio da cidade.

Tal, salvo melhor juizo, o meu parecer.

Rio de Janeiro, 28 de fevereiro, 1915

RUY BARBOSA

Vae no rascunho original, qual me saiu, ao correr da penna, este manuscripto, que, por evitar demora, envio assim mesmo, pedindo o favor de me remetterem uma copia dactylographica, e esperando me relevem as incorrecçóes. 